\title{
Epistemic Value and Achievement
}

\section{Daniel Whiting}

The definitive version of this article is to be published in Ratio (2012) by Wiley-Blackwell, and will be available at http://onlinelibrary.wiley.com/.

\section{Introduction}

Knowledge seems to be a good thing, or at least better than epistemic states, statuses or conditions that fall short of it, such as mere true belief. Though it is notoriously difficult to account for the value knowledge appears to possess, ${ }^{1}$ that knowledge is valuable seems to be a deep-rooted conviction widely-shared by philosophers and non-philosophers alike, which might in part explain the considerable amount of attention the concept of knowledge receives in recent and not-so-recent philosophy.

In the contemporary literature, however, there appears to be a growing sense that philosophers, in focusing the bulk of their efforts on knowledge—as well as related epistemic notions such as justification —have neglected the concept of understanding. ${ }^{2}$ One, though not the only, reason for thinking that understanding deserves our attention, and so for thinking that this is indeed a case of neglect, is that understanding seems to be something which we value highly. Indeed, it is at least arguable that we value understanding more highly than we value other epistemic states, statuses or conditions on which philosophers have traditionally focused, most notably knowledge. 
In a number of recent publications, Duncan Pritchard has advanced an account of understanding which is intended to account for the distinctive value it seems to possess. ${ }^{3}$ That account, which appeals to the idea that understanding is a cognitive achievement, has yet to receive much, if any, critical attention. In this paper, I shall outline Pritchard's explanation of understanding's value and the accompanying conception of achievement. While I will not deny that understanding is valuable, or at least more valuable than epistemic states which fall short of it, I shall reject Pritchard's explanation of this fact.

Though the initial focus of what follows is the details of Pritchard's particular proposal, I shall go on to extract a more general lesson. According to it, a certain sort of approach—of which Pritchard's is one instance and of which there are many others - to explaining the value of a given epistemic state-whether it be understanding, knowledge, or whatever - is in principle misguided. Any such approach, I shall argue, could only really explain the value of coming to be in the relevant epistemic state, rather than the value of being in that state; thus, it looks, at best, like it offers the right answer to the wrong question. I shall shed light on this no doubt dark claim in due course.

\section{Understanding and achievement}

Before proceeding, it is important to note that there are many species of understanding, including:

- propositional understanding (e.g., understanding that public spending has been cut);

- objectual understanding (e.g., understanding David Cameron, or understanding physics); 
- understanding how (e.g., understanding how to jumpstart a car);

- $\quad$ understanding wh- (e.g., understanding why William the Conqueror invaded England, understanding when it is time to leave, or understanding what happened to the cookies).

In this paper, following Pritchard, I shall focus primarily on understanding $w h$-and, more specifically, on understanding why (hereafter, all talk of 'understanding' should be read as concerning understanding why). Whether what Pritchard has to say about understanding why extends to other species of understanding and whether, in turn, my objections to what he has to say extend in a like manner are interesting questions but beyond the scope of this paper.

No doubt understanding is often of instrumental value. Understanding why a certain disease takes hold, for example, might enable us to cure it. But Pritchard's aim is not to show that understanding is sometimes valuable, perhaps as a means to other things we value, or even that it is valuable in general as a means to other things we value; rather, his aim is to reveal understanding as such to be 'distinctively, and hence finally, valuable', at least other things being equal. ${ }^{4}$

As mentioned above, Pritchard's account of the value of understanding appeals to the notion of achievement. In Pritchard's view, 'it is plausible to hold that the kind of successes that count as achievements are valuable for their own sake because of how they are produced', at least other things being equal. In support of this, he writes:

Imagine, for example, that you are about to undertake a course of action designed to attain a certain outcome and that you are given the choice between merely being successful in what you set out to do, and being successful in such a way that you exhibit achievement. Suppose further that it is stipulated in advance that there are no practical costs or benefits to choosing either way. Even so, wouldn't you prefer to 
exhibit achievement? And wouldn't you be right to do so? If that is correct, then this is strong evidence for the final value of achievements. ${ }^{5}$

One might challenge the view that achievements are finally valuable or the informal considerations Pritchard musters in support of that view. I shall grant both and consider instead whether one can appeal to the value of achievement in accounting for the value of understanding.

Pritchard distinguishes two theses concerning achievement: ${ }^{6}$

(WEAK) Achievements are successes that are because of ability.

(STRONG) Achievements are successes that are because of ability where the success in question either involves the overcoming of a significant obstacle or the exercise of a significant level of ability.

In Pritchard's view, (STRONG) captures our ordinary conception of achievement as something of value. I shall question this later, but Pritchard is certainly right that (WEAK) is too weak. Suppose you set me the task of picking up a mug of tea and I succeed. Though my success is due to my physical ability, it is hardly an achievement, let alone a valuable achievement. (That said, if one does not share this estimation, nothing in what follows rests on it.)

With this in place, Pritchard's account of the value of understanding falls into place. Understanding, he claims, is a cognitive success that is because of cognitive ability, and so it is a cognitive achievement. ${ }^{7}$ Since achievements in general are, at least qua achievements, finally valuable, it follows that understanding is finally valuable. 


\section{$3 \quad$ Understanding without achievement}

Clearly there are many cases in which one's arriving at an understanding is an achievement. But is it in the nature of understanding as such to be an achievement in the (STRONG) sense? Does understanding always involve achievement? No. To appreciate this, consider the following example (call it, (SLUG)). As I pass the lettuces in my garden, I spot slugs. I thereby come to understand why my lettuces are failing - because slugs are eating them. This is a familiar case of understanding, one whose acquisition does not appear to involve, as (STRONG) requires, 'the overcoming of a significant obstacle'.

Of course, overcoming a significant obstacle is only one way in which, according to (STRONG), a success can be an achievement. The other way is for the success to involve 'the exercise of a significant level of ability'. Accordingly, while Pritchard accepts that understanding may be 'gained with ease'-i.e. in the absence of great challenges and without 'undertaking an obstacle-overcoming effort to piece together the relevant pieces of information'- - he insists that, when so gained, 'one is bringing to bear significant cognitive ability'.

However, suppose that, in the case of (SLUG), I simply notice the sorry state of the lettuce, notice the slugs eating its leaves, and put two and two together. The level of cognitive ability exercised seems minimal. Consider also the following case (call it, (MILK)). I see my son knocking a glass of milk and spilling its contents on to the floor. I thereby come to understand why there is milk on the floor-because my son knocked the glass and spilled the milk on to the floor. In this case, I do not even have to put two and two together; that is, I do not have to find the link between my son's actions and the spilled milk; I simply see the spilling of the milk. The degree of cognitive ability exercised here is negligible. 
One difficulty in settling this issue is that it is not clear when a level of ability counts as 'significant', so at the least Pritchard should say more about that. That said, there is a dilemma lurking here. On the one hand, if Pritchard construes 'a significant level of ability' in a very undemanding way—so that, for example, I count in (SLUG) or (MILK) as exercising it — he seems to be reverting to the conception of achievement captured by (WEAK), which, for good reason, he rejects. On the other hand, if Pritchard construes 'a significant level of ability' in a demanding way, it becomes implausible to suggest that understanding always involves its exercise-as (SLUG) and (MILK) show.

Even if suitable guidance on this matter is forthcoming, does (STRONG) really capture our ordinary conception of achievement as something valuable? I doubt that success due to the exercise of a significant level of ability is sufficient for achievement. To adapt Pritchard's example, imagine that Tiger Woods sinks his hundredth putt from a considerable distance. No doubt 'there is great skill on display', as Pritchard says, ${ }^{9}$ but is there achievement? Perhaps to have sunk one hundred putts in a row is an achievement but that does not show that sinking any one of those putts is an achievement, especially if Woods finds any such shot effortlessly easy. To appreciate this, place yourself in Woods' shoes. One can imagine, as he sinks putt after putt with the most casual swing of the club, his sense of achievement diminishing, perhaps precisely because he misses the challenge. This, in effect, is to suggest that (STRONG) is false - a success that is because of ability might count as an achievement if the success in question involves the overcoming of a significant obstacle, but it does not count as an achievement if it only involves the exercise of a significant level of ability. 
So, even if a case could be made that there is a sense in which the examples of acquiring understanding described in (SLUG) and (MILK) involve a significant level of cognitive skill, it does not follow that they involve achievement.

Even if it turns out that (STRONG) is defensible, and even if Pritchard offers an account of what it is to exercise a significant level of skill that manages both not to be weak and to accommodate (SLUG) and (MILK), there seem to be many cases of acquiring an understanding which are not successes that are because of ability, and so not achievements according to (STRONG) or (WEAK). Consider the following example (call it, (SON)). Suppose that my son returns from the garden to tell me why the lettuces are failing (because the slugs are eating them). I thereby come to understand why the lettuces are failing. In this case, my cognitive success is not primarily due to my cognitive abilities but to my son's. Thus, there is no cognitive achievement. Of course, my cognitive abilities do play a part in my coming to understanding, but I do not come to understand because of those abilities.

Perhaps Pritchard is assuming that, in a case like (SON), my success is because of my abilities, since, if I am to understand why the lettuces are failing, I have to 'piece together' the information my son provides. However, let us simply stipulate that it is my son who pieced together the information, information which he then passed, pieced together, to me, perhaps by saying, 'The lettuces are failing because the slugs are eating them'.

In response, one might continue to insist that the success in the case of (SON) is due to my cognitive abilities; after all, it involves exercising my ability to recognise what my son is telling me, to recognise a reliable informant, and so on. However, to make an ad hominem point, whatever is to be said for this, this is not a response available to Pritchard. When discussing an analogous example involving knowledge, 
he claims that to insist that such success is primarily creditable to one's cognitive ability would 'involve denying some pretty strong intuitions' and someone who takes this 'line will face a tough uphill struggle'. ${ }^{10}$ Moreover, to make the point less ad hominem, Pritchard is surely right. To exploit an example he uses for a different end, (SON) seems analogous to a case in which someone who lacks archery abilities is being assisted by a skilled archer in firing an arrow and is thereby successful. (For example, the skilled archer helps the novice to take aim, steadies his arm, corrects [his] posture, and so on.) While the unskilled archer's abilities might have played some role in the successful outcome-such that it is to some degree creditable to him that he is successful—-we would surely say that this success is primarily creditable to the skilled archer (or, at least, creditable to the combined efforts of the unskilled archer and the skilled archer). We certainly would not regard the success in question as being primarily creditable to the novice archer. On this basis, then, we would maintain that the unskilled archer's success does not constitute a bona fide achievement. ${ }^{11}$

By the same token, we should not count my success in (SON) as a bona fide achievement according to either (STRONG) or (WEAK). If Pritchard wants to insist that it does, he faces 'a tough uphill struggle'.

One option, hinted at by Pritchard's parenthetical remarks, might be to insist that the success in (SON) is due to the 'combined efforts' of me and my son, and hence qualifies as a joint achievement. This would be enough to preserve the thought that understanding is, qua achievement, finally valuable; whether that achievement is individual or shared is immaterial.

There are, of course, cases in which two or more individuals arrive at an understanding through joint cognitive labour. Unfortunately for Pritchard, (SON) is not such a case; it is not one in which my son and I together come to understand why 
the lettuces are failing but one in which my son acquired this understanding without my help. Even if it could be shown that his doing so was an achievement, it was not our achievement; the understanding was already arrived at, and I simply took advantage of it. So, the genuine possibility of acquiring an understanding through sharing skills does nothing to show that all understanding involves achievement.

To summarise, I have raised a question as to whether (STRONG) is strong enough to capture our ordinary conception of achievement as something of value. Even if it is, cases like (SLUG) and (MILK) seem to show that one can have understanding without achievement in the (STRONG) sense. And cases like (SON) seem to show that one can have understanding without achievement in even the (WEAK) sense. Since understanding need not involve achievement, Pritchard cannot account for understanding's final value in terms of the final value of achievement. This is not to deny that achievement and understanding are valuable, finally or otherwise, or to deny that understanding can involve achievement; it is only to deny that the value of understanding in general is (an instance of) the value of achievement.

\section{$4 \quad$ Understanding, luck and difficulty}

Since, as I argued above, it seems not to be the case that coming to understand necessarily constitutes a valuable achievement, why would one think otherwise? In this section, I shall turn to the considerations Pritchard offers in support of his view and argue that, although in light of them one can appreciate why one might be attracted to such a view, those considerations do not in fact support the claim that acquiring an understanding is an achievement.

Part of Pritchard's case for the claim that understanding is a cognitive achievement rests on the idea that achievements in general are compatible with 
environmental luck. ${ }^{12}$ To use his example, imagine that an archer takes aim at a target in challenging weather conditions. The archer releases the arrow and, due to his skill, hits the target. Intuitively, this is an achievement. Suppose further that the archer happened to aim at the one target in the range that is not protected by an invisible force-field. In that case, the success involves a certain sort of luck but it seems to count as an achievement nonetheless. In just the same way, Pritchard argues, understanding is compatible with environmental luck (in this respect, he maintains, understanding differs from knowledge, which is not compatible with such luck). To use his example, suppose that I ask a person dressed as a fire-officer why my house burned down. That person tells me that it was due to faulty-wiring, which 'coheres with [my] wider set of beliefs', ${ }^{13}$ and I thereby come to understand why my house burned down. Suppose further that I just happened to ask the one of the many people in the area dressed as fire-officers who is a genuine fire-officer. In that case, my epistemic standing involves a certain sort of luck but it seems to count as understanding nonetheless.

One might challenge the claim that understanding is compatible with environmental luck. While I have my suspicions, I shall grant it. At most, that claim shows that understanding is like cognitive achievement, and unlike knowledge, in not being undermined by a certain sort of luck, which I do not deny; it does not show that understanding always results from cognitive achievement.

The second consideration Pritchard adduces in support of the claim that all understanding involves cognitive achievement is as follows. ${ }^{14}$ There are cases in which one has 'knowledge without exhibiting the corresponding cognitive achievement'. Call these cases of easy knowledge. These are also cases in which one lacks understanding, which, Pritchard claims, suggests that understanding and 
achievement go hand in hand. To adapt Pritchard's example, suppose that I tell my infant son that the house burned down due to faulty-wiring. It is natural to think that my son thereby comes to know why the house burned down, but his doing so is not an achievement; his knowledge is not primarily creditable to his abilities but to mine. Moreover, since my son 'has no conception of how faulty wiring might cause a fire', he does not understand why the house burned down.

If such cases are genuine, and I grant that they are, it hardly shows that all understanding involves achievement; at most, it shows that some cases in which one lacks understanding are also cases in which no achievement is exhibited. Moreover, one can allow that, in the above example, my son would have acquired an understanding if he had displayed a cognitive achievement of the relevant sort, but what Pritchard needs to demonstrate is that my son would have acquired an understanding only if he had displayed such a cognitive achievement.

That said, it is not difficult to see why, in focusing on such cases, one might be led to Pritchard's view. The above is a case in which one has knowledge but in which one lacks understanding. Since the knowledge is easy, it is tempting to think that what has to be added to arrive at understanding is difficulty, perhaps the sort of difficulty which presents an obstacle or the overcoming of which requires significant skill, i.e. the sort the surmounting of which involves achievement. However, tempting as this line of thought might be, it is mistaken. At most, the above shows that, in cases like the one at hand, if not in others, one has to do more to understand than to know and so that, in that respect, understanding is more difficult to win than knowledge; it does not follow that the difficulty involved is the sort that presents challenges the meeting of which would be creditable to the exercise of the cognitive abilities of the subject on that occasion. 
It is plausible to think that my son's lack of understanding in the above example is due in part to his lacking the relevant background beliefs with which to integrate his newly acquired information. Crucially, there is no obvious reason to think that, if my son were to have the relevant background beliefs, and if his newly acquired information were to be integrated with those beliefs, this would be attributable to the exercise of a significant level of skill on his part, let alone in the face of great obstacles. Perhaps my son just finds himself saddled with those beliefs and the integration of the new information is either utterly straightforward or something that simply happens to him, not something he does or can take credit for.

These remarks are not intended as a contribution to an account of the conditions necessary or sufficient for understanding. For present purposes, the point is simply that it does not immediately follow from the fact that, in certain cases, understanding calls for more than knowledge that, in those cases and all others, understanding calls for achievement in overcoming obstacles or in exercising significant skill. At the very least, Pritchard needs to say a lot more to show that it does, and the previous section gives reason to doubt that such a case will be forthcoming. Nonetheless, while the considerations Pritchard offers do not support his claim that understanding always involves cognitive achievement, attending to them has shed some light on the attraction that view might seem to have.

Maybe there are responses available to Pritchard to the above points, which he could appeal to in order to show that, despite appearances, understanding really does always involve achievement in a suitably strong sense. However, I worry how wellmotivated the search for such responses would be, for reasons I shall explore in the next section. 


\section{$5 \quad$ Epistemic value and achievement}

I am happy to grant that understanding is valuable, or at least better than epistemic states that fall short of it. However, I doubt that achievement is the right place to look for an explanation of this, or, for that matter, for an explanation of the value of other epistemic states, including knowledge.

I have suggested that Pritchard's particular attempt to explain the value of understanding by appeal to the value of achievement fails. That attempt is just one instance of a more general tendency to attempt to explain the value of a given epistemic state, including knowledge, by appeal to the achievement acquiring it involves, or by appeal to the successful exercise of certain cognitive abilities which results in that state. In the remainder of this paper, I shall suggest that attempts of this sort do not look very promising, quite apart from their details.

Although not all use the language of achievement, appeals to notions of that sort are central to many accounts of epistemic value, especially to virtue-theoretic accounts. According to Ernest Sosa, for example, a true belief constitutes knowledge only if it is 'apt', that is, only if it is true because it is the result of the subject's skill, adroitness, or competence. ${ }^{15}$ In turn, this is supposed to explain how knowledge might be something of 'fundamental value'. ${ }^{16}$ The thought, presumably, is that exercising one's 'epistemic virtues' in a way that results in accurate belief is, like apt performance in general, valuable. In a similar fashion, John Greco holds that knowledge is a kind of success from ability, and in general success from ability is both intrinsically valuable and constitutive of human flourishing, which is also intrinsically valuable. Moreover, both success from ability and human flourishing have 'final' value, or value as ends in themselves, independently of any instrumental value that they might also have. ${ }^{17}$ 
Since Greco views understanding as a species of knowledge — specifically, knowledge of causes in the Aristotelian sense- he might tell a similar story about the value of understanding. ${ }^{18}$ Finally, Wayne Riggs maintains, very roughly, that knowledge is true belief 'due to your own powers and abilities' and 'that this "credit-worthiness" feature of knowledge is what makes it distinctively valuable'. ${ }^{19}$

These all represent attempts, like Pritchard's, to account for the value of an epistemic state such as knowledge or understanding by appeal to the idea that the relevant state is a success attributable to the skill or ability of the subject. Above $(\S 2)$, some doubt was cast on the idea that mere success from ability - that is, achievement in the (WEAK) sense-is valuable. Moreover, I suspect considerations like those adduced above $(\S 3)$ could be used to show that knowledge, like understanding, need not result from achievement in the (STRONG) sense. But, setting these concerns aside, and so granting that the relevant epistemic states are significant successes because of ability, I shall question whether appealing to that fact holds much promise as an explanation of the value of such states.

Whether or not a success is an achievement is an etiological matter; it concerns how it came about it (say, through the overcoming of obstacles). In that case, one might expect that appealing to achievement could at most account for the value of arriving at an epistemic state, not of being in it, of acquiring an epistemic status, not of having it. Compare the following. Climbing to the summit of Mount Everest is a great achievement and to that extent valuable. It does not follow that sitting on the summit of Mount Everest is an achievement, let alone valuable, even if one could only sit on the summit of Mount Everest having climbed there. Similarly, creating the world's largest rubber band ball might be an achievement, and so to some extent valuable. But it is far from clear that what results from this achievement—a large 
rubber band ball or, indeed, the status of having made a large rubber band ball—is valuable; both the aforementioned upshots seem worthless.

One might complain that these cases are disanalogous to cases of knowledge and the like in an important respect. A subject's being on the summit of Mount Everest, for example, is externally related to the exercise of skill responsible for it, which is to say that that state or her being in it does not represent or embody achievement. In contrast, on the view under consideration, a subject's being in the relevant epistemic state is internally related to the exercise of skill responsible for it, which is to say that that state or her being in it does represent or embody achievement.

This point does not get the proponent of the view under consideration very far. Compare the following. To characterise someone as the winner of a competition to make the world's largest rubber band ball is to characterise her as both successful and creditable for that success. A subject's being the winner of such a competition is, then, internally related to her having enjoyed an achievement of sorts. However, while winning the competition might have been valuable, insofar as it was an achievement, being the winner of the competition, a status one might enjoy long after having acquired it, does not appear valuable in the slightest; at most, it is the status of having done something of value, rather than a valuable status to have. Likewise, if it is true that to characterise an epistemic state as, say, knowledge is to characterise it as a successful result creditable to the subject in that state, this would only show that knowledge, a state one might enjoy long after having arrived at it, is a state of having done something of value, rather than a valuable state to be in.

Even in cases where the achievement and what results from the achievement are both valuable, the value might not be the same in each case. Suppose that one graduates from a top university with a first-class degree. Assuming that this success is 
creditable to one's skills, perhaps in the face of great social and intellectual obstacles, graduating represents or embodies a considerable achievement, and so is something of corresponding value. Moreover, being a graduate of such an institution in possession of such a qualification is no doubt valuable too, though in different ways; perhaps it is conducive to a successful career, a generous salary, and so forth. So, being a graduate both is an enduring state or condition which is valuable in certain respects and indicates or entails that the person in that state or condition has displayed a valuable achievement, namely graduating, but the value of the former does not appear to be explained by or reducible to the value of the latter.

The point is not that being a graduate is only instrumentally valuable, in contrast to the final value of graduating - for all I say here, being a graduate might be finally valuable too. The point is only that the good of being a graduate and the good of graduating look like different goods, even though one could only be a graduate having graduated. Returning to the issue at hand, a certain enduring epistemic state or condition might both be valuable in certain respects and indicate or entail that the person in that state or condition has displayed a valuable cognitive achievement, without the value of the former being the same as or reducible to the value of the latter.

\section{$6 \quad$ Concluding remarks}

I have suggested that to look for the value of an epistemic state in the achievement reaching it involves is to look in the wrong place. Even if it were true that one can have knowledge or understanding only through achievement, which I doubt for reasons outlined above with respect to understanding, this would appear at most to 
account for the value of coming to know or understand, not of knowing or understanding, that is, of arriving at the relevant epistemic state, not of being in it.

These considerations - which are not intended to cast doubt on virtue-theoretic theories of epistemic states but only on certain virtue-theoretic and like-minded explanations of the value such states seem to possess - are, I admit, not decisive as they stand. But they do give some reason to be sceptical about the prospects of trying to account, as many do, for the value of knowledge, understanding and the like in etiological terms.

Any such scepticism might prompt one to revise one's judgements about the epistemic value of the relevant states while paving the way for an account that will explain away the appearance of value which is responsible for such judgements. Perhaps the relevant state is not distinctively valuable and the intuition to the contrary is the result of wrongly projecting on to the state the value of the achievement that coming to be in it allegedly involves. An alternative, which I would recommend, would be to hold on to the judgements about the epistemic value of the relevant states and look elsewhere for a story which vindicates them. ${ }^{20}$

\section{Notes}

${ }^{1}$ For discussion of the difficulties, see J. Kvanvig, The Value of Knowledge and the Pursuit of Understanding (Cambridge: Cambridge University Press, 2003).

${ }^{2}$ For views of this sort, see Kvanvig, The Value of Knowledge, esp. ch. 8; J. Kvanvig, 'The Value of Understanding' in Epistemic Value, ed. A. Haddock, A. Millar and D. Pritchard (Oxford: Oxford University Press, 2009); W. Riggs, 'Understanding Virtue and the Virtue of Understanding' in Intellectual Virtue, ed. M. DePaul and L. Zagzebski (Oxford: Oxford University Press, 2003); and L. Zagzebski, 'Recovering 
Understanding' in Knowledge, Truth, and Duty, ed. M. Steup (Oxford: Oxford University Press, 2001).

${ }^{3}$ See 'Recent Work on Epistemic Value', American Philosophical Quarterly 44 (2007), pp. 85-110; 'The Value of Knowledge' in Stanford Encyclopedia of Philosophy, ed. E. Zalta (2007), URL: http://plato.stanford.edu/entries/knowledgevalue/; 'Knowing the Answer, Understanding and Epistemic Value', Grazer Philosophische Studien 77 (2008), pp. 325-39; 'Knowledge, Understanding and Epistemic Value' in Epistemology, ed. A. O’Hear (Cambridge: Cambridge University Press, 2009); and 'Knowledge and Understanding' in D. Pritchard, A. Millar and A. Haddock, The Nature and Value of Knowledge: Three Investigations (Oxford: Oxford University Press, 2010).

${ }^{4}$ Pritchard, 'Knowledge and Understanding', p. 66.

${ }^{5}$ Pritchard, 'Knowledge and Understanding', pp. 29-30. Cf. Pritchard, 'Knowledge, Understanding and Epistemic Value', §4.

${ }^{6}$ Pritchard, 'Knowledge and Understanding', p. 70.

${ }^{7}$ As Pritchard says, 'all understanding involves cognitive achievement' ('Knowledge and Understanding', p. 82).

${ }^{8}$ Pritchard, 'Knowledge and Understanding', p. 82-83.

${ }^{9}$ Pritchard, 'Knowledge and Understanding', p. 68.

${ }^{10}$ Pritchard, 'Knowledge and Understanding', p. 42.

${ }^{11}$ Pritchard, 'Knowledge and Understanding', p. 43.

${ }^{12}$ See 'Knowing the Answer'; 'Knowledge, Understanding and Epistemic Value’, §6;

'Knowledge and Understanding', §2.5.

${ }^{13}$ Pritchard, 'Knowledge and Understanding', p. 78. 
${ }^{14}$ See 'Knowledge, Understanding and Epistemic Value', §14; 'Knowledge and Understanding', $\S 4.5$.

${ }^{15}$ See E. Sosa, A Virtue Epistemology: Apt Belief and Reflective Knowledge (Oxford: Oxford University Press, 2007), esp. ch. 2.

${ }^{16}$ Sosa, Virtue Epistemology, p. 88.

${ }^{17}$ J. Greco, Achieving Knowledge: A Virtue Theoretic Account of Epistemic Normativity (Cambridge: Cambridge University Press, 2010), p. 99.

${ }^{18}$ On understanding, see Greco, Achieving Knowledge, p. 9. Note that, in Greco's view, understanding possesses a value distinct from and additional to that which knowledge per se possesses (see p. 145). Greco might not try to account for the distinctive value he attributes to understanding in the manner explored here. ${ }^{19}$ W. Riggs, 'Luck, Knowledge, and Control' in Epistemic Value, ed. A. Haddock, A. Millar and D. Pritchard (Oxford: Oxford University Press, 2009), p. 220.

${ }^{20}$ Thanks to Charlie Pelling, Conor McHugh for feedback on an earlier version of this material. Thanks also to John Cottingham for suggestions that greatly improved the paper. 